\title{
RESULTS FROM THE INFRARED SPECTROSCOPY EXPERIMENT ON MARINER 9
}

J. PEARL, B. CONRATH, R. CURRAN, R. HANEL, V. KUNDE, and J. PIRRAGLIA Goddard Space Flight Center, Greenbelt, Md., U.S.A.

Abstract. Over 20000 thermal emission spectra of Mars have been obtained, providing extensive diurnal, seasonal and spatial coverage of the planet. Each spectrum covers the spectral range from 200 to $2000 \mathrm{~cm}^{-1}$ with an apodized spectral resolution of $2.4 \mathrm{~cm}^{-1}$; the noise equivalent radiance of the instrument is $0.5 \times 10^{-7} \mathrm{~W}$ $\mathrm{cm}^{-2} \mathrm{sr}^{-1}\left(\mathrm{~cm}^{-1}\right)^{-1}$.

Data obtained during the dust storm $\left(290^{\circ}<L_{s}<320^{\circ}\right)$ contain broad spectral features due to entrained dust which are centered near 480 and $1090 \mathrm{~cm}^{-1}$; from these features the $\mathrm{SiO}_{2}$ content of the dust material is estimated to be $60 \pm 10 \%$. Radiative transfer calculations for model dust clouds suggest particle radii of a few micrometers. By using a Stokes-Cunningham-settling and turbulent-atmospheric-mixing model, the observed secular cooling of the atmosphere can be explained in terms of dust particles having radii of $\sim 1 \mu \mathrm{m}$ and an atmospheric eddy diffusion coefficient somewhat in excess of $10^{6} \mathrm{~cm}^{2} \mathrm{~s}^{-1}$ during the settling phase of the dust storm. Atmospheric temperature profiles during this period showed large diurnal excursions $( \pm 15 \mathrm{~K})$ and strongly subadiabatic lapse rates $\left(\sim 1.5 \mathrm{~K} \mathrm{~km}^{-1}\right)$. Wind fields derived from these data show a strong tidal behavior, with wind speeds above the surface boundary layer of roughly $40 \mathrm{~m} \mathrm{~s}^{-1}$ for midlatitudes; the accompanying diurnal surface pressure variations were about $\pm 5 \%$. Large scale temperature wave structures have been discovered in the atmosphere with $\sim 5 \mathrm{~K}$ amplitudes; these are found to be caused by the interaction of the diurnal heating wave with the strong wavenumber 2 component of the planetary topography. Atmospheric water vapor concentrations of $\sim 10$ precipitable micrometers were observed at southern and midnorthern latitudes, with no detectable amounts over the north polar region.

Following the clearing of the dust $\left(320^{\circ}<L_{s}<350^{\circ}\right)$ atmospheric temperatures in the stratosphere decreased $\sim 30 \mathrm{~K}$ while the lapse rate increased to about $3 \mathrm{~K} \mathrm{~km}^{-1}$. Between latitudes of $25^{\circ} \mathrm{N}$ and $65^{\circ} \mathrm{S}$, surface pressure mapping indicates that the highest pressures $(\sim 9 \mathrm{mb})$ occur in Hellas and in Isidis Regio. The lowest pressure observed $(\sim 1.5 \mathrm{mb})$ was near the top of South Spot $\left(-9^{\circ}, 120^{\circ}\right)$; pressures could not be determined for the other shield volcanoes. Clouds in the north polar hood have been conclusively identified as being composed of water ice. They are found at pressures exceeding $2.0 \mathrm{mb}$ and are generally in the temperature range of $160-180 \mathrm{~K}$.

Later less extensive coverage $\left(45^{\circ}<L_{s}<80^{\circ}\right)$ indicated further cooling of the upper atmosphere to $155 \mathrm{~K}$, but a stabilization of the lapse rate at $3 \mathrm{~K} \mathrm{~km}^{-1}$. Water vapor vanished over the south polar region, remained nearly constant at $\sim 10 \mu \mathrm{m}$ in the equatorial region, increased to as much as $50 \mu \mathrm{m}$ at mid-northern latitudes, and increased to $\sim 30 \mu \mathrm{m}$ over the north polar region. Clouds observed in the Tharsis area 
have also been conclusively identified as composed of water ice particles a few micrometers in size.

\section{DISCUSSION}

Beer: Would you explain the basis upon which the $60 \%$ silicate content of the dust was found?

Pearl: The features in the standard deviation of the spectra which I have shown give us a measure of the dust transmittance as a function of wavelength. From the general positions of these features we conclude that they arise from silicate minerals rather than other minerals, such as calcium carbonate, which has a much different spectral behaviour. From a more detailed comparison of the widths of the features, and the positions of these maxima and minima with laboratory data, we conclude that the dust is of largely intermediate silica content.

Icke: Does the direction of your derived wind velocity field coincide with the direction of the blackand-white streaks on the surface?

Pearl: Yes.

Low: Do your spectra give information about surface composition?

Pearl: In principle, yes. However, the persistence of the atmospheric dust has hampered the interpretation, because the spectral features of the dust occur in the same region as the spectral features of the surface.

Low: Does this mean that the method is invalidated as a tool for remote sensing of surface composition on Mars?

Pearl: The question is unresolved. By making nearly simultaneous observations of a given area at different viewing angles, the effects of the dust can be eliminated in the analysis. Unfortunately, we have very few such measurements, and their reduction is incomplete.

Golitsyn: What is the mean radius of the particles, and what amount of dust is in a unit column of the atmosphere?

Pearl: The mean radius is $1-2 \mu \mathrm{m}$, and the mean dust content is about $200 \mu \mathrm{g} \mathrm{cm}^{-2}$.

Kliore: Was there any evidence of dust in spectra taken during the latter part of the mission?

Pearl: In some there appears to be little dust, in others a considerable amount. In general, there was much less than in the early part of the mission.

Gehrels: Did you observe Phobos and Deimos?

Pearl: Phobos was observed, but as it filled only a small portion of the field of view, the signal-tonoise ratio is low; our reductions of the Phobos data are still in progress. 